\title{
SEPARATION OF THE MAGNETIC FRACTION FROM THE SLAGS ORIGINATED DURING STEEL PRODUCTION
}

\author{
${ }^{1}$ Kryštof FONIOK, 'Vlastimil MATĚJKA, ${ }^{2}$ Petra MAIEROVÁ, ${ }^{3}$ Petra MATĚJKOVÁ, ${ }^{2}$ Jozef VLČEK \\ ${ }^{1}$ VŠB - Technical University of Ostrava, Faculty of Materials Science and Technology, Department of \\ Chemistry, Ostrava, Czech Republic, EU \\ ${ }^{2}$ VŠB - Technical University of Ostrava, Faculty of Materials Science and Technology, Department of \\ Thermal Engineering, Ostrava, Czech Republic, EU

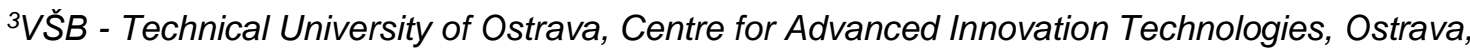 \\ Czech Republic, EU, krystof.foniok@vsb.cz
}

\section{https://doi.org/10.37904/metal.2021.4092}

\begin{abstract}
Metallurgical slags originating during pig iron and steel manufacturing, are valuable sources of the inorganic materials. The limitation of their recycling is usually connected to the expensive methods of the separation of the components. The steel furnace slags (FS) as well as ladle slags (LS) contains reasonable amount of iron bonded in different forms, predominantly in iron oxides. In this paper we are reporting the results of the dry and wet separation techniques used for the isolation of the magnetic fraction presented in FS and LS. The results obtained indicate the dry magnetic separation as not suitable for this purpose, while wet method was found to be promising. In this research the FS containing approx. 30 wt $\%$ of $\mathrm{Fe}_{2} \mathrm{O}_{3}$ and LS containing approx. $17 \mathrm{wt} \%$ of $\mathrm{Fe}_{2} \mathrm{O}_{3}$ were milled to the fraction less than $0.1 \mathrm{~mm}$ and then subjected to the process of dry and wet separation of the magnetic fraction. It was observed that the dry separation is not suitable, since $100 \%$ of the materials were recovered showing the intensive homogenization of the magnetic fraction during the milling process. On the other hand, the wet separation led to the isolation of 26 and $30 \mathrm{wt} \%$ of magnetic fractions for FS and LS, respectively. The isolated magnetic fractions contained 41 and $40 \mathrm{wt} \%$ of $\mathrm{Fe}_{2} \mathrm{O}_{3}$ in the case of the FS and LS, respectively. The fractions obtained during the separation were subjected to the chemical and phase analysis, the morphology of the particles was studied using scanning electron microscopy.
\end{abstract}

Keywords: Metallurgical slags, magnetic separation, iron recovery

\section{INTRODUCTION}

In 2021 the metallurgical slags production reached approximately 350 million tons per year. Disposal of the slags, which are in fact the source of the valuable minerals, became difficult as a result of more stringent environmental regulations and thus the searching of the suitable methods for the separation of their components are highly demanding. The slags originating during cast iron and steel production can be divided into three main categories: blast furnace (BF) slags, steel furnace slags (FS) and ladle slags (LS) $[1,2]$.

Blast furnace slags contributes more than half to overall amount of the slag produced in the iron and steel making industry. However, they are used in cement and building industry in high extent, what makes them a valuable by-product and are not considered as the waste materials. On the other hand, due to the high value of non-ferrous metals and decreasing of the number of the sources of high-grade ores such non-metals, slag is considered as their secondary source. Thus, increasingly complex and expensive processes are becoming viable options to treat non-ferrous slags. However, effective recycling of steel slags (FS and LS), as the second largest group of the slags (after BF) remains a problem. The processing of these slags may not be economically 
advantageous, but on the other hand the presence of heavy metals, free lime and iron oxide does not allow their use in typical construction applications [3].

Within EU and the other industrialized countries, on average more than $70 \%$ of steel slags are utilized in road constructions, cement production, and marine structures. However, there are still millions of tons of unused steel slags in the EU [4]. Different techniques for recovery of the minerals/metals presented in the slags have been studied and utilized for a long time. They can be sub-divided into two main groups: i) physical and ii) chemical methods. The physical methods used for the separation of the components forming the slag are based on the difference in at least one of their physical property (e.g. density, magnetic susceptibility and wettability). The chemical methods involve at least one chemical reaction in the process and can be divided to pyrometallurgical and hydrometallurgical methods [5]. Most of the integrated steel plants recover the bulk metal pieces present in the slag by magnetic separation [6]. The very small particles $(<0.5 \mathrm{~mm})$ occurring in slag are not intended to be recovered as its recovery is not feasible mainly from the technical-economic point of view. The total amount of metallic part associated with the slags is around $3-8 \%$ of the weight of the slag depending on the used production process. The magnetic process, in principle, separates the magnetic part (mostly metallic material covered with other non-magnetic impurities) from the slag mixture in different size fraction [7].

The crushing and grinding efficiency and strength of the magnetic field that is employed in the process define the degree of slag being carried along with the metal [8]. The magnetic fraction obtained during the separation process is a mixture of diverse magnetic materials, not only pure iron. Iron oxides in slag $\left(\mathrm{FeO}\right.$ and $\left.\mathrm{Fe}_{3} \mathrm{O}_{4}\right)$ are also magnetic and are attracted to magnet and carried together with the metal pieces. Thus, complete separation of the slag from the metal is not possible [9]. The magnetic part does not necessarily mean metallic only but it contains unseparated slag and magnetic oxide as well [10]. The recycling of the slag components has made important progress in the recent years [11]. In research institutes, the technique used for effective recycling of iron primarily includes dry magnetic separation of bulk slag, wet stage grinding and magnetic separation, wet magnetic separation for full grain level, fine-grained level flotation, and gravity separation [12]. Usually, the wet magnetic separation method is used to separate the metallic iron particles form the slag powder [13].

In this work we studied the difference between dry magnetic separation and wet magnetic separation on a very fine FS and LS slag fraction $(<0.1 \mathrm{~mm})$. The chemical composition of the obtained magnetic and non-magnetic fractions were characterized using $X$-ray fluorescence spectroscopy, phase composition was studied using Xray diffraction method. Scanning electron microscopy was used for the observation of the particles morphology.

\section{MATERIALS AND METHODS}

\subsection{Studied materials}

Two slags, FS and LS originated during steel making process were studied and their chemical composition is shown in Table 1. Calcium oxide is the dominant component of both slags as evident from Table 1. Both FS as well as LS consists of significant amount of iron (in Table 1 expressed as $\mathrm{Fe}_{2} \mathrm{O}_{3}$ ).

Table 1 Chemical compositions of original slags (wt.\%)

\begin{tabular}{|c|c|c|c|c|c|c|c|}
\hline \multirow{2}{*}{ Samples } & \multicolumn{7}{|c|}{ Components } \\
\cline { 2 - 8 } & $\mathrm{MgO}$ & $\mathrm{Al}_{2} \mathrm{O}_{3}$ & $\mathrm{SiO}_{2}$ & $\mathrm{CaO}$ & $\mathbf{S O}_{3}$ & $\mathrm{MnO}$ & $\mathrm{Fe}_{2} \mathrm{O}_{3}$ \\
\hline FS & 3.57 & 1.53 & 9.40 & 47.93 & 0.14 & 4.38 & $\mathbf{2 9 . 7}$ \\
\hline LS & 2.82 & 5.83 & 12.11 & 52.91 & 1.20 & 2.76 & $\mathbf{1 6 . 9}$ \\
\hline
\end{tabular}


In order to liberate the metallic iron from the slags, the received slag was stepwise crushed by a jaw crusher (Brio s.r.o., Czech Republic) followed by the vibration milling (Testchem, Poland). A jaw crusher with a feeding size smaller than $80 \mathrm{~mm}$ and discharging size smaller than $15 \mathrm{~mm}$ was employed in the primary crushing of both slags in order to adjust the particle size of slags prior the milling with vibration mill. The vibration mill with a feeding size smaller than $5 \mathrm{~mm}$ and discharging size of $>0.020 \mathrm{~mm}$, was employed in the further crushing. The mild slags were then classified by a sieve with aperture sizes 100 micron.

\subsection{Magnetic separation experiments}

Dry magnetic separation: A sample of slag weighing $50 \mathrm{~g}$ was spread in a thin layer. Subsequently, a neodymium magnet was moved over the sample at a height of $30 \mathrm{~mm}$ to separate the magnetic and nonmagnetic components.

Wet magnetic separation: experiments were carried out using a glass beaker on which a belt with neodymium magnets was placed on the outside wall. Typically, about $5 \mathrm{~g}$ of the slag was put into a glass beaker and mixed with $300 \mathrm{~mL}$ of water. The obtained suspension was then stirred 5 min using Mechanical Overhead Stirrer (Heidolph Model RZR 2041) operated at 250 RPM in order to homogenise the suspension. A belt of neodymium magnets was then placed on the outer wall of the glass vessel and the suspension was next stirred for 10 minutes. During this process, most of the strong magnetic particles presented in slag adhered to the glass wall, and the nonmagnetic materials fell into a bottom part of the beaker. Subsequently, the non-magnetic fraction was separated by the filtration. Finally, after removing of the magnets, the magnetic fraction felt to the bottom of the beaker and small amount of the water was added. After that the magnetic fraction was separated by filtration. Both, magnetic and non-magnetic fractions were dried at $70{ }^{\circ} \mathrm{C}$ and weighed.

\subsection{Characterization of the slags}

Chemical composition of the original slags and individual fraction of the slags obtained during magnetic separation was performed on wave dispersive X-ray fluorescence spectrometer Supermini 200 (Rigaku, Japan) equipped with Pd tube (200W) and scintillation counter and F-PC detector.

Phase composition of the samples was studied using Theta/2Theta X-ray diffractometer MiniFlex600 (Rigaku, Japan) equipped with Co tube $(600 \mathrm{~W})$ and D/teX Ultra detector. Samples pressed in rotational holders were analysed in reflection mode.

Scanning electron microscope Aspex Explorer (ThermoFisher Scientific, USA) equipped with thermionic emission source CeB6, secondary electron and back scattered electron detector was used for the characterization of the slag particles. Energy dispersive detector was used for local chemical analysis.

\section{RESULTS AND DISCUSSION}

The yields of the magnetic fractions obtained by dry as well as wet procedure for both FS and LS is shown in Table 2.

Table 2 Yield of magnetic fractions for dry and wet separation procedure

\begin{tabular}{|c|c|c|}
\hline \multirow{2}{*}{ Samples } & Separation procedure & Magnetic fraction (\%) \\
\hline \multirow{2}{*}{ LS } & Dry & 100 \\
\cline { 2 - 3 } & Wet & 26 \\
\hline \multirow{2}{*}{ FS } & Dry & 100 \\
\cline { 2 - 3 } & Wet & 30 \\
\hline
\end{tabular}


As evident, usage of the dry procedure in the case of both types of slags let to the yield $100 \%$ (Table 2). This fact could be attributed to the intensive homogenization of the magnetic and non-magnetic phases during the milling with vibration mill. So, the simple dry separation procedure could not be considered as the efficient milling method used for the micronization of the slags intended for the magnetic separation.

On the other hand, the wet procedure let to the decrease in magnetic fractions yields for FS and LS to 30 and $26 \%$, respectively (Table 2). These results indicate the efficiency of the wet separation of magnetic fractions for both FS and LS. With respect to the obtained results, further chemical and phase analysis was performed only for the fractions obtained with wet magnetic separation.

The chemical composition of the magnetic (M) and non-magnetic (NM) fractions for both slags is shown in

Table 3.

Table 3 Chemical compositions of magnetic (M) and non-magnetic (NM) part for wet magnetic separation (wt.\%)

\begin{tabular}{|c|c|c|c|c|c|c|c|c|}
\hline \multirow{2}{*}{ Samples } & \multirow{2}{*}{ Fraction } & \multicolumn{7}{|c|}{ Components } \\
\cline { 2 - 9 } & & $\mathbf{M g O}$ & $\mathrm{Al}_{2} \mathrm{O}_{3}$ & $\mathrm{SiO}_{2}$ & $\mathbf{C a O}$ & $\mathbf{S O}_{3}$ & $\mathbf{M n O}$ & $\mathrm{Fe}_{2} \mathrm{O}_{3}$ \\
\hline \multirow{3}{*}{$\mathrm{FS}$} & $\mathrm{M}$ & 3.75 & 1.22 & 7.07 & 37.46 & 0.19 & 6.11 & $\mathbf{4 0 . 9}$ \\
\cline { 2 - 10 } & $\mathrm{NM}$ & 3.97 & 1.69 & 10.31 & 44.37 & 0.24 & 4.08 & $\mathbf{2 8 . 1}$ \\
\hline \multirow{2}{*}{ LS } & $\mathrm{M}$ & 3.27 & 3.28 & 8.08 & 37.83 & 0.69 & 5.30 & 39.5 \\
\cline { 2 - 10 } & $\mathrm{NM}$ & 3.20 & 5.89 & 12.28 & 56.39 & 1.13 & 1.95 & $\mathbf{1 1 . 5}$ \\
\hline
\end{tabular}

Comparing the data in Table 3 with the chemical composition of the original slags (Table 2) the enrichment of the magnetic fraction by $\mathrm{Fe}_{2} \mathrm{O}_{3}$ to approximately $40 \mathrm{wt} . \%$ in the case of both slags is clearly observable. The amount of $\mathrm{Fe}_{2} \mathrm{O}_{3}$ in non-magnetic fractions of both slags signalize there is still reasonable amount of iron containing phases which should be separated.

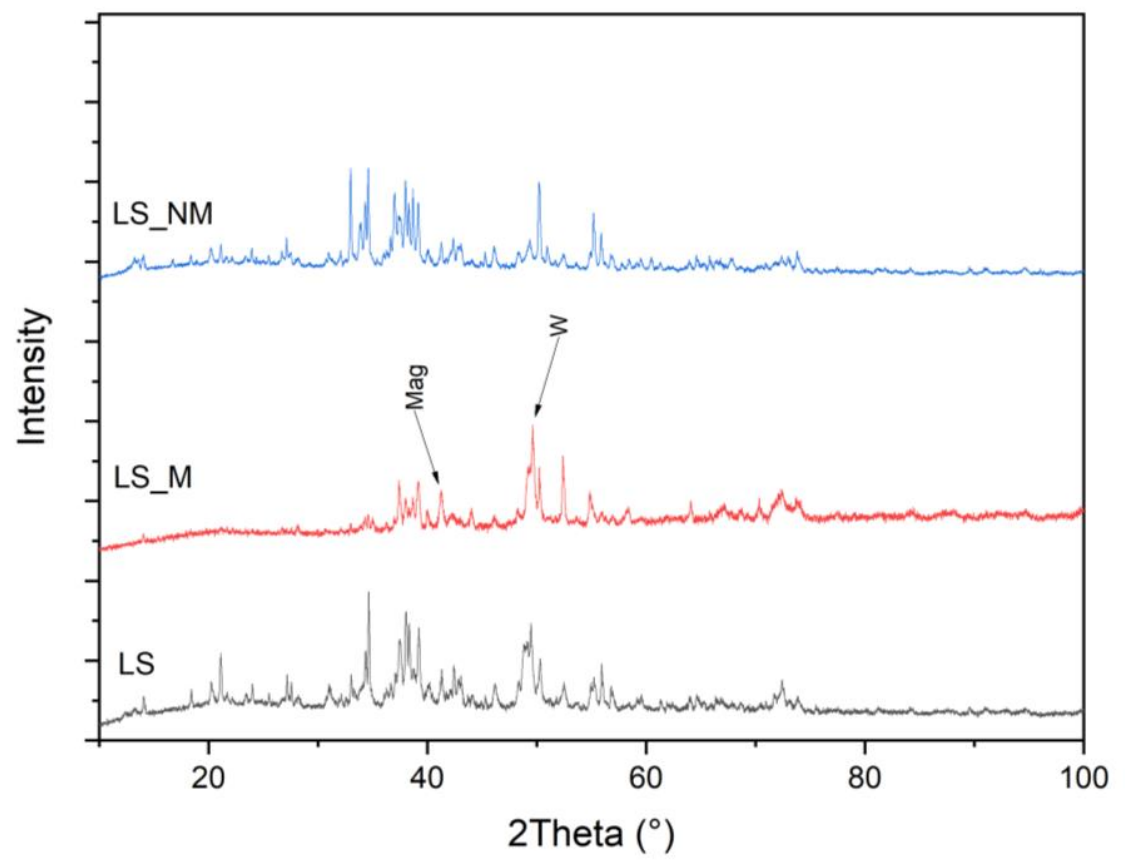

Figure $1 \mathrm{XRD}$ patterns of the original LS sample compared with XRD patterns of magnetic (M) and nonmagnetic (NM) fractions obtained by wet magnetic separation. (Mag ... magnetite, W ... wüstite). 
X-ray diffraction patterns of magnetic and non-magnetic fractions obtained from LS slag are shown in Figure 1. The most intensive diffraction lines for identified major iron containing phases: magnetite ( $\mathrm{Fe} 3 \mathrm{O} 4)$ and wüstite (FeO) are depicted in Figure 1.

X-ray diffraction patterns show more pronounced enrichment of magnetic fraction with wüstite and the diffraction pattern of non-magnetic fraction shows persistence of the magnetite in this fraction.

The non-magnetic fraction of LS sample was subjected to SEM analysis and the obtained image with point EDX spectra are shown in Figure 2.

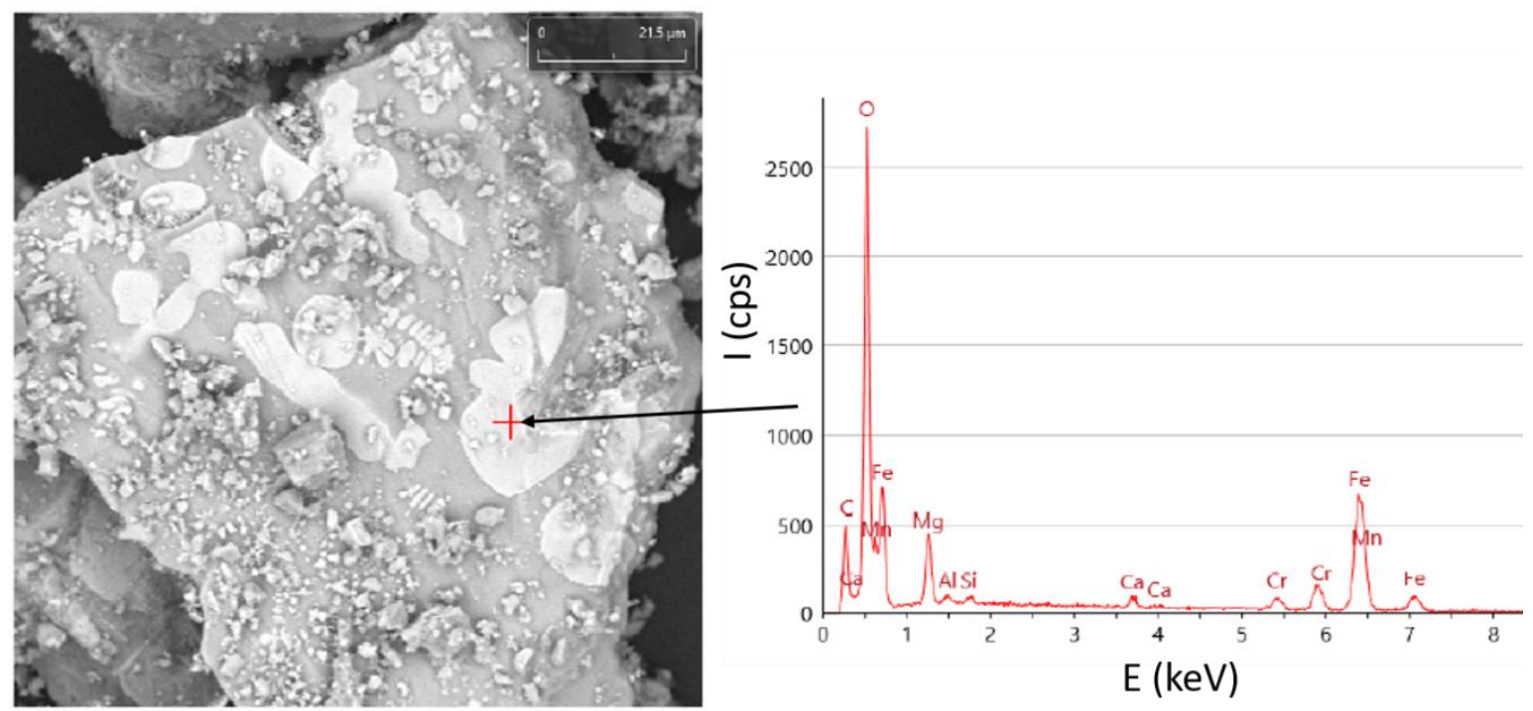

Figure 2 SEM micrograph of the selected particle of non-magnetic fraction of LS sample together with EDX spectra measured in marked point.

The SEM image of the selected particle shown in Figure 2 depicts the main reason for remaining content of iron in non-magnetic fraction. The iron-bearing phases are firmly embeded in the dense matrix composed of magnesium, aluminium, calcium, silicon and oxygen. So complex phase was not identified by XRD method and thus the area of the particle appeared in light-grey colour is most probably of amorphous character. To isolate iron-bearing phases held in a such matrix the different milling procedure has to be searched.

\section{CONCLUSIONS}

The dry and wet separation techniques were used for the isolation of the magnetic fraction presented in FS and LS. It was observed that the dry separation is not suitable, since $100 \%$ of the materials were recovered as magnetic fraction, showing the intensive homogenization of the magnetic fraction during the milling process. With respect to this result, the dry magnetic separation cannot be considered as suitable for the separation of the magnetically active iron based phases from fine grained slags. Using the wet method, the separation led to the isolation of 26 and $30 \mathrm{wt} . \%$ of magnetic fractions for FS and LS, respectively. Obtained magnetic fractions were enriched by 11 and 23 wt. $\%$ of $\mathrm{Fe}_{2} \mathrm{O}_{3}$ for $\mathrm{FS}$ and LS samples if compared with the $\mathrm{Fe}_{2} \mathrm{O}_{3}$ content analysed in pristine FS and LS samples. The chemical analysis of non-magnetic fractions proved elevated amount of the iron. The observation of the particles presented in non-magnetic fraction with SEM revealed the fact, that small particles of iron-bearing phases are firmly encased in the complex, most probably amorphous matrix. This observation highlights the necessity for the searching of the milling technique which enables to liberate the particles of these small iron containing phases. 


\section{ACKNOWLEDGEMENTS}

This work was supported by projects "Research on the management of waste, materials and other products of metallurgy and related sectors" (CZ.02.1.01/0.0/0.0/17_049/0008426).

\section{REFERENCES}

[1] SVIRIDOVA, T., BOBROVA, O., ILINA, O., NEKEROV, E. Development of steelmaking slag processing scheme for environmental stress reduction. Journal of Physics: Conference Series. 2019, vol. 1399, pp. 1-6.

[2] GOLIK, V., DMITRAK, Y., RAZORENOV, Y., MASLENNIKOV, S., LYASHENKO, V. Mechanochemical technology of iron extraction from enrichment tailings. Ferrous Metallurgy. 2021, vol. 64, pp. 282-291.

[3] SVIRIDOVA, T., BOBROVA, O., PERYATINSKY, A., NEKEROV, E. Evaluation of the influence of slag heaps on the state of the urban residential area. In: IOP Conference Series: Materials Science and Engineering. Bristol; IOP Publishing: 2019, vol. 537, pp. 1-6.

[4] SVIRIDOVA, T., BOBROVA, O., ILINA, O., PERYATINSKY, A., STAROSTINA, N. Elaboration of steelmaking slag processing scheme for resource-saving. In: IOP Conference Series: Materials Science and Engineering. Bristol; IOP Publishing: 2018, vol. 411, pp. 1-4.

[5] YU Q. Metal recovery from steelmaking slag. Toronto, 2017. Master thesis. Department of Materials Science and Engineering University of Toronto.

[6] FRUEHAN, R. J. The making, shaping, and treating of steel. Pittsburgh: AISE Steel Foundation, 1998.

[7] ALANYALI, H., ÇÖL, M., YILMAZ, M. a KARAGÖZ Ş. Application of magnetic separation to steelmaking slags for reclamation. Waste Management. [online]. 2006, vol. 26, pp. 1133-1139. Available from:

https://doi.org/10.1016/j.wasman.2006.01.017.

[8] HUITING, S., FORSSBERG, E. An overview of recovery of metals from slags. Waste Management. [online]. 2003, vol. 23, pp. 933-949. Available from: https://doi.org/10.1016/S0956-053X(02)00164-2

[9] YANG, D., BOZZATO, P., FERRARA, G. Iron Ore Beneficiation with Packed Column Jig. Journal of Minerals and Materials Characterization and Engineering. 2003, vol. 02, pp. 43-51.

[10] DILDIN, A., CHUMANOV, I. Study of the Processes of Metal Recovery from Steel Slags. Indian Journal of Science and Technology. [online]. 2015, vol. 8, pp. 1-7. Available from: https://doi.org/10.17485/ijst/2015/v8i34/85338.

[11] SRIPRIYA, R., MURTY, C. Recovery of metal from slag/mixed metal generated in ferroalloy plants a case study. International Journal of Mineral Processing. 2005, vol. 75, pp. 123-134.

[12] LI, Y., YAO, Y., WANG, L. Recycling of industrial waste and performance of steel slag green concrete. Journal of Central South University of Technology. [online]. 2009, vol. 16, pp. 768-773. Available from: https://doi.org/10.1007/s11771-009-0128-X.

[13] MENAD, N., KANARI, N., SAVE, M. Recovery of high grade iron compounds from LD slag by enhanced magnetic separation techniques. International Journal of Mineral Processing. 2014, vol. 126, pp. 1-9. 